\title{
Commentary: On the Interpretation of the Normalization Constant in the Scaling Equation
}

\author{
Douglas S. Glazier* \\ Department of Biology, Juniata College, Huntingdon, PA, United States
}

Keywords: allometry, body size, autocorrelation, biological meaning of scaling coefficients and exponents, metabolic-level boundaries hypothesis

\section{A Commentary on}

On the Interpretation of the Normalization Constant in the Scaling Equation

by Niklas, K. J., and Hammond, S. T. (2019). Front. Ecol. Evol. 6:212. doi: 10.3389/fevo.2018.00212

Many biological size-scaling relationships follow the power function $Y=\beta X^{\alpha}$, where $Y$ is a specific trait, $\beta$ is the normalization constant (scaling coefficient), $X$ is a measure of size, and $\alpha$ is the slope (scaling exponent). Niklas and Hammond (2019) have argued that, although much investigation has focused on the empirical values and biological meaning of $\alpha$, comparable attention has not been given to $\beta$. They also evaluate four possible reasons for why they think $\beta$ has been understudied, including a belief by some investigators (e.g., Huxley, 1932) that $\beta$ has no biological meaning, and that its value is often merely the result of a statistical autocorrelation with $\alpha$. Their thoughtful argument for increasing investigation of the biological meaning of $\beta$ is worthwhile reading, but I feel that it leaves out three important points. First, the authors do not mention or even hint at the existence of numerous studies on the scaling of various physiological, anatomical, and lifehistory traits that show how various factors affect $\beta$ in biologically meaningful ways. Second, they do not discuss alternative ways of quantifying the elevation of a scaling relationship (conventionally estimated as $\beta$ ) that avoid the autocorrelation problem. Third, they do not recognize previous noteworthy literature concerning the scaling of metabolic rate that has focused on understanding both the elevation and slope, and the relationship between the two. Given space limitations, I can only provide a brief discussion of these three points. Readers can find further details in the cited references, some of which are reviews of relevant theory and empirical data.

First, many studies have examined how various factors affect the elevation (as indicated by $\beta=$ antilog of the Y-intercept in a log-log plot) of the body-mass scaling of metabolic rate and other traits. For example, much research has shown that temperature and behavioral activity increase metabolic rate at all body sizes, and thus the overall scaling elevation (e.g., Brown et al., 2004; Glazier, 2010). Furthermore, consider that comparative studies of various biological traits often adjust for body-size effects by using analysis of covariance. These countless studies in effect compare the elevations (as indicated by Y-intercepts) of multiple size-scaling relationships, which are assumed to be parallel (i.e., $\alpha$ is constant; see Sokal and Rohlf, 1995). This statistical method thus emphasizes $\beta$ over $\alpha$, which is reasonable if $\alpha$ is fixed. Indeed, proponents of the 3/4-power law claim that $\alpha$ is fixed at $3 / 4$ for rates of metabolism and other biological processes, and that variation in these scaling relationships principally involves $\beta$ (e.g., Brown et al., 2004). An early example was reported by Hemmingsen (1960), whose well-known analysis of metabolic scaling revealed significant differences in $\beta$ between unicellular ectotherms, multicellular ectotherms, and multicellular endotherms, but no inter-group differences in $\alpha(\sim 3 / 4)$. Several researchers have 
discussed biological reasons for not only this variation in scaling elevation (e.g., Phillipson, 1981; Peters, 1983; Glazier, 2014a), but also that of many other kinds of physiological, anatomical, and life-history traits among various taxa (e.g., Peters, 1983; SchmidtNielsen, 1984; Hayssen and Lacy, 1985; Zotin, 1990; Sibly and Brown, 2007; Glazier, 2009a, 2018a). Biologically meaningful analyses of $\beta$ have not been as neglected as claimed by Niklas and Hammond.

Second, although Niklas and Hammond correctly point out that $\beta$ and $\alpha$ of multiple intersecting scaling relationships may correlate for simple mathematical reasons, this may occur even if the relationships do not intersect. When comparing multiple scaling relationships, if $\beta$ tends to be less than the geometric midpoint of a scaling relationship, $\beta$ and $\alpha$ will tend to be negatively correlated, whereas if $\beta$ tends to be greater than the midpoint, $\beta$ and $\alpha$ will tend to be positively correlated. Many investigators of scaling relationships have recognized this autocorrelation effect (e.g., Gould, 1966; Peters, 1983; Glazier, 2010, 2018c). To avoid this problem, $\beta$ can be replaced with another measure of scaling elevation, $L$, which is $\log (Y / X)$ at the pivotal midpoint of a log-log scaling relationship. For metabolic scaling relationships, this measure of elevation (metabolic level) may relate to the slope in a biologically meaningful way that is not a simple mathematical artifact (e.g., Glazier, 2009b, 2010, 2014b; Killen et al., 2010). However, the $L$ estimate is most useful when comparing non-proximate, non-intersecting scaling relationships with similar body-mass ranges. For example, large variation in the midpoint mass at which one estimates $L$ can potentially confound relationships between the elevation and slope (Glazier, 2009b, 2010). Evidence for biologically significant correlations between the elevation and slope of scaling relationships is strongest when similar results are found for both $\beta$ and $L$ (Glazier, 2009b, 2010).

Third, several researchers not cited by Niklas and Hammond have explored both the elevation and slope of scaling relationships and their correlation. For example, Heusner (1991) emphasized that metabolic scaling relationships cannot be fully understood without explaining their vertical location in a "mass-power plane." McNab (2008, 2009) showed how several ecological and biological factors affect both the slope

\section{REFERENCES}

Brown, J. H., Gillooly, J. F., Allen, A. P., Savage, V. M., and West, G. B. (2004). Toward a metabolic theory of ecology. Ecology 85, 1771-1789. doi: 10.1890/03-9000

Glazier, D. S. (2005). Beyond the '3/4-power law': variation in the intra-and interspecific scaling of metabolic rate in animals. Biol. Rev. 80, 611-662. doi: $10.1017 /$ S1464793105006834

Glazier, D. S. (2008). Effects of metabolic level on the body size scaling of metabolic rate in birds and mammals. Proc. R. Soc. B Biol. Sci. 275, 1405-1410. doi: $10.1098 /$ rspb.2008.0118

Glazier, D. S. (2009a). Metabolic level and size scaling of rates of respiration and growth in unicellular organisms. Funct. Ecol. 23, 963-968. doi: $10.1111 / \mathrm{j} .1365-2435.2009 .01583 . x$

Glazier, D. S. (2009b). Ontogenetic body-mass scaling of resting metabolic rate covaries with species-specific metabolic level and body size in spiders and elevation of metabolic scaling relationships in birds and mammals (see also other references cited in Glazier, 2010). Price and Weitz (2012) have examined correlations between the scaling intercepts and slopes of leaf surface area. In particular, Glazier (2005, 2008, 2010, 2014b) proposed the metaboliclevel boundaries hypothesis $(\mathrm{MLBH})$, which predicts that the elevation and slope of scaling relationships should be negatively correlated for resting metabolic rate, but positively correlated for active metabolic rate. The MLBH further predicts that any factor that affects the elevation of metabolic scaling relationships (quantified as $\beta$ or $L$ ), including temperature, physiological state, and activity level, will in turn affect the slope via shifts in the relative influence of various metabolic processes that relate to either surface area or volume. Many studies have tested the MLBH, often with confirming results (reviewed in Glazier, 2008, 2009a, 2010, 2014b, 2018b).

Investigations of the biological meaning of both the elevations and slopes of scaling relationships of some physiological, anatomical, and life-history traits are already underway, and similar efforts should be worthwhile for other kinds of biological traits, as advocated by Niklas and Hammond (2019). In so doing, I recommend that researchers become well-versed in the available, widely scattered literature on diverse kinds of organisms to be sure that they do not inadvertently rediscover or miss valuable insights regarding scaling patterns or explanations that have already been reported, a common occurrence in the field of biological scaling (Glazier, 2018c).

\section{AUTHOR CONTRIBUTIONS}

The author confirms being the sole contributor of this work and has approved it for publication.

\section{FUNDING}

This work was funded by the Juniata College.

\section{ACKNOWLEDGMENTS}

DG thanks the reviewers for their helpful comments. and snakes. Comp. Biochem. Physiol. A Mol. Integr. Physiol. 153, 403-407. doi: 10.1016/j.cbpa.2009.03.020

Glazier, D. S. (2010). A unifying explanation for diverse metabolic scaling in animals and plants. Biol. Rev. 85, 111-138. doi: 10.1111/j.1469-185X.2009.00095.x

Glazier, D. S. (2014a). Metabolic scaling in complex living systems. Systems 2, 451-540. doi: 10.3390/systems2040451

Glazier, D. S. (2014b). Scaling of metabolic scaling within physical limits. Systems 2, 425-450. doi: 10.3390/systems2040425

Glazier, D. S. (2018a). "Clutch mass, offspring mass, and clutch size: body-mass scaling and taxonomic and environmental variation" in The Natural History of the Crustacea, Volume 5: Life Histories, eds G. A. Wellborn, and M. Thiel (Oxford: Oxford University Press), 67-95.

Glazier, D. S. (2018b). Effects of contingency versus constraints on the body-mass scaling of metabolic rate. Challenges 9:4. doi: 10.3390/challe90 10004 
Glazier, D. S. (2018c). Rediscovering and reviving old observations and explanations of metabolic scaling in living systems. Systems 6:4. doi: 10.3390/systems6010004

Gould, S. J. (1966). Allometry and size in ontogeny and phylogeny. Biol. Rev. 41, 587-638. doi: 10.1111/j.1469-185X.1966.tb01624.x

Hayssen, V., and Lacy, R. C. (1985). Basal metabolic rates in mammals: taxonomic differences in the allometry of BMR and body mass. Comp. Biochem. Physiol. A Physiol. 81, 741-754. doi: 10.1016/0300-9629(85)90904-1

Hemmingsen, A. M. (1960). Energy metabolism as related to body size and respiratory surface, and its evolution. Rep. Steno Mem. Hosp. 9, 1-110.

Heusner, A. A. (1991). Size and power in mammals. J. Exp. Biol. 160, 25-54.

Huxley, J. S. (1932). Problems of Relative Growth. London: Methuen.

Killen, S. S., Atkinson, D., and Glazier, D. S. (2010). The intraspecific scaling of metabolic rate with body mass in fishes depends on lifestyle and temperature. Ecol. Lett. 13, 184-193. doi: 10.1111/j.1461-0248.2009.01415.x

McNab, B. K. (2008). An analysis of the factors that influence the level and scaling of mammalian BMR. Comp. Biochem. Physiol. A Mol. Integr. Physiol. 151, 5-28. doi: 10.1016/j.cbpa.2008.05.008

McNab, B. K. (2009). Ecological factors affect the level and scaling of avian BMR. Comp. Biochem. Physiol. A Mol. Integr. Physiol. 152, 22-45. doi: 10.1016/j.cbpa.2008.08.021

Niklas, K. J., and Hammond, S. T. (2019). On the interpretation of the normalization constant in the scaling equation. Front. Ecol. Evol. 6:212. doi: $10.3389 /$ fevo.2018.00212

Peters, R. H. (1983). The Ecological Implications of Body Size. Cambridge: Cambridge University Press. doi: 10.1017/CBO9780511 608551
Phillipson, J. (1981). "Bioenergetic options and phylogeny" in Physiological Ecology: An Evolutionary Approach to Resource Use, eds C. R. Townsend and P. Calow (Sunderland, MA: Sinauer Associates), 20-45.

Price, C. A., and Weitz, J. S. (2012). Allometric covariation: a hallmark behavior of plants and leaves. New Phytol. 193, 882-889. doi: 10.1111/j.1469-8137.2011.04022.x

Schmidt-Nielsen, K. (1984). Scaling: Why Is Animal Size so Important? Cambridge: Cambridge University Press. doi: 10.1017/CBO9781139167826

Sibly, R. M., and Brown, J. H. (2007). Effects of body size and lifestyle on evolution of mammal life histories. Proc. Natl. Acad. Sci. U.S.A. 104, 17707-17712. doi: 10.1073/pnas.0707725104

Sokal, R. R., and Rohlf, F. J. (1995). Biometry: The Principles and Practice of Statistics in Biological Research, 3rd Edn. New York, NY: Freeman.

Zotin, A. I. (1990). Thermodynamic Bases of Biological Processes: Physiological Reactions and Adaptations. Berlin: Walter de Gruyter. doi: $10.1515 / 9783110849974$

Conflict of Interest: The author declares that the research was conducted in the absence of any commercial or financial relationships that could be construed as a potential conflict of interest.

Copyright (C) 2020 Glazier. This is an open-access article distributed under the terms of the Creative Commons Attribution License (CC BY). The use, distribution or reproduction in other forums is permitted, provided the original author(s) and the copyright owner(s) are credited and that the original publication in this journal is cited, in accordance with accepted academic practice. No use, distribution or reproduction is permitted which does not comply with these terms. 